\title{
Correction to: Entrepreneurial Competencies of SME Owners: A Comparative Exploratory Analysis Between Iran and Italy
}

\author{
Afsaneh Bagheri and Emidia Vagnoni
}

\section{Correction to:}

Chapter 22 in: N. Faghih, M. R. Zali (eds.), Entrepreneurship

Ecosystem in the Middle East and North Africa (MENA),

Contributions to Management Science,

https://doi.org/10.1007/978-3-319-75913-5_22

The original version of this chapter was published with incorrect authorship. The second author name was inadvertently omitted. The authorship has been updated with this erratum. Afsaneh Bagheri and Emidia Vagnoni are the authors of this chapter. 